XVI Encontro Sobre a Cultura do Amendoim

15 a 17 de agosto de 2019 na Estação de Eventos Cora Coralina e FCAV/UNESP,

Jaboticabal-SP

\title{
TIODICARBE NO CONTROLE DE LAGARTA-DO-PESCOÇO-VERMELHO EM AMENDOIM
}

Carlos Cesar de Oliveira Guarnieri ${ }^{1}$; Gabriel Alberto Ceballos ${ }^{1}$; Tamara Ribeiro Silva ${ }^{1}$; Renato Paes Junior $^{1}$

${ }^{1}$ Departamento técnico Rotam do Brasil Agroquímicos LTDA, Campinas, SP, carlosguarnieri@rotam.com

RESUMO: O trabalho teve como objetivo avaliar os efeitos de diferentes doses de inseticidas aplicados isoladamente ou combinados, na infestação, porcentagem de controle, porcentagem de folíolos danificados e produtividade no amendoim (Arachis hypogaea L.), sob população natural de lagarta-do-pescoço-vermelho (Stegasta bosqueella). O delineamento experimental utilizado foi em blocos casualizados com 8 tratamentos e 4 repetições. Os tratamentos foram: 1) tiodicarbe 240, 2) tiodicarbe 320 3) tiodicarbe 400,4$)$ tiodicarbe $160+$ abamectina 9,5) tiodicarbe $240+$ abamectina 9 , 6) tiodicarbe 320 + abamectina 9 7) clorantraniliprole $20+$ abamectina $9\left(\mathrm{~g}\right.$ i.a ha $\left.{ }^{-1}\right)$ e testemunha sem aplicação. As aplicações foram realizadas aos 40, 54 e 68 dias após a emergência (DAE). Os dados foram submetidos à análise de variância pelo teste $\mathrm{F}$ e as comparações das médias pelo teste ScottKnott a $5 \%$ de probabilidade. Conclui-se que as doses isoladas de tiodicarbe 320 , tiodicarbe 400 e as combinações tiodicarbe 160 + abamectina 9 , tiodicarbe 320 + abamectina 9 e clorantraniliprole $20+$ abamectina $9\left(\mathrm{~g}_{\text {i.a ha }}{ }^{-1}\right)$ apresentaram os menores valores de porcentagem de folíolos.

Palavras-Chave: Arachis hypogaea L., Stegasta bosqueella, Predom, eficácia, manejo, controle químico.

\section{INTRODUÇÃO}

O amendoim (A. hypogaea L.) é uma leguminosa de origem sul-americana e sua composição é rica em óleo, proteínas e vitaminas. Na safra 2018/2019 foram produzidas no Brasil 431 mil toneladas em uma área de 144 mil hectares, com grande expressividade no Estado de São Paulo correspondendo a $94 \%$ da produção total do país (Conab, 2019).

Embora apresente grande importância econômica no estado, alguns problemas fitossanitários como a ocorrência de pragas desencadeiam grandes prejuízos na cadeia produtiva da cultura. Dentre as principais pragas, destaca-se a Stegasta bosqueella (Chambers) (Lepidoptera: Gelechiidae), conhecida como lagarta-do-pescoço-vermelho (Gallo et al., 2002), lagartas atacam os folíolos novos ainda fechados, perfurando-os de forma simétrica, comprometendo a área fotossintética ocasionando perda na produtividade do amendoim. 


\section{Encontro Sobre a Cultura do Amendoim \\ 15 a 17 de agosto de 2019 na Estação de Eventos Cora Coralina e FCAV/UNESP, Jaboticabal-SP}

A principal forma de controle da praga é através da utilização de produtos químicos, quando constatada $60 \%$ de plantas atacadas e pelo menos dois folíolos com perfurações em ambos os lados por folha (Almeida, 2015). Neste contexto o trabalho teve como objetivo avaliar os efeitos de diferentes doses de inseticidas aplicados isoladamente ou combinados na infestação, porcentagem de controle, porcentagem de folíolos danificados e produtividade do amendoim sob população natural de lagarta-do-pescoço-vermelho.

\section{MATERIAL E MÉTODOS}

O experimento foi realizado no município de Artur Nogueira, SP nas coordenadas $22^{\circ} 31^{\prime} 48^{\prime \prime} \mathrm{S}$ e $47^{\circ} 07^{\prime} 01^{\prime \prime} \mathrm{O}$ com $710 \mathrm{~m}$ de altitude. O clima é quente e temperado e pode ser caracterizado como Cwa na classificação de Köppen com $19,8^{\circ} \mathrm{C}$ de temperatura média e $1295 \mathrm{~mm}$ de pluviosidade média anual. O solo da área é identificado como Latossolo Vermelho férrico de textura média.

A cultivar utilizada foi IAC OL3 foi semeada no dia 12/11/2018, tendo como cultura antecessora o milho. O delineamento experimental utilizado foi em blocos casualizados, contendo oito tratamentos e quatro repetições. Cada parcela foi composta por 6 linhas espaçadas de 0,5 metros cada, totalizando 3,0 metros de largura e 5,0 metros de comprimento, perfazendo uma área de 15,0 $\mathrm{m}^{2}$. Foram utilizadas as duas linhas centrais, desprezando-se $1,5 \mathrm{~m}$ de bordadura de cada lado do comprimento, totalizando área útil de $1,0 \mathrm{~m}^{2}$. As sementes foram tratadas com tiametoxam e carboxina + tiram, para controle de plantas daninhas realizou-se após a semeadura a aplicação de sulfentrazona e S-metolacloro as doenças foram manejadas rotacionando clorotalonil, piraclostrobina + epoxiconazol e fluxapiroxade + piraclostrobina.

Os tratamentos adotados e suas respectivas doses estão apresentados na Tabela 1.

Tabela 1. Tratamentos de inseticida para controle de lagarta-do-pescoço-vermelho ( $S$. bosqueella) na cultura do amendoim. Arthur Nogueira, SP, safra 2018/19.

\begin{tabular}{|c|c|c|c|}
\hline \multirow{2}{*}{ Tratamentos } & \multirow{2}{*}{ Ingrediente ativo } & \multicolumn{2}{|c|}{ Doses } \\
\hline & & i.a. ${ }^{1}\left(\mathrm{~g} \mathrm{ha}^{-1}\right)$ & p.c. $^{2}\left(\mathrm{~mL}\right.$ ou $\left.\mathrm{g} \mathrm{ha}^{-1}\right)$ \\
\hline Predom $®$ & tiodicarbe & 240 & 300 \\
\hline Predom® & tiodicarbe & 320 & 400 \\
\hline Predom $®$ & tiodicarbe & 400 & 500 \\
\hline Predom $\AA+$ Grimectin $\AA$ & tiodicarbe + abamectina & $160+9$ & $200+500$ \\
\hline Predom $®+$ Grimectin $\AA$ & tiodicarbe + abamectina & $240+9$ & $300+500$ \\
\hline Predom $®+$ Grimectin $®$ & tiodicarbe + abamectina & $320+9$ & $400+500$ \\
\hline Premio $®$ + Grimectin $®$ & clorantraniliprole + abamectina & $20+9$ & $100+500$ \\
\hline Testemunha sem aplicação & - & - & - \\
\hline
\end{tabular}




\section{Encontro Sobre a Cultura do Amendoim}

15 a 17 de agosto de 2019 na Estação de Eventos Cora Coralina e FCAV/UNESP, Jaboticabal-SP

${ }^{1}$ i.a $=$ ingrediente ativo, ${ }^{2} \mathrm{p} . \mathrm{c}=$ produto comercial.

Para aplicação dos tratamentos utilizou-se pulverizador costal pressurizado com $\mathrm{CO}$, acoplado a uma barra de pulverização de seis pontas do tipo leque (Teejet Turbojet Série 110 02) e volume de calda de $200 \mathrm{~L} \mathrm{ha}^{-1}$. As aplicações foram realizadas aos 40, 54 e 68 dias após a emergência (DAE).

Foram realizadas 4 avaliações, a primeira com um dia de antecedência da aplicação inicial (Prévia), a segunda sete dias após a primeira aplicação (7 DA1A), a terceira sete dias após a segunda aplicação (7 DA2A) e a quarta, sete dias após a terceira aplicação (7 DA3A). Em cada avaliação, foram contabilizados a presença da lagarta-do-pescoço-vermelho em 10 folíolos novos e em 10 flores amostrados aleatoriamente por parcela. Na última avaliação 75 DAE quantificou-se 20 folíolos por parcela e determinou-se a porcentagem de folíolos danificados. Para efeitos de comparações entre tratamentos, utilizou-se a fórmula de porcentagem de controle proposta por Abbott, 1925. A colheita foi realizada para obtenção da produtividade logo após o ponto de maturação fisiológica da cultura.

Os dados foram submetidos à análise de variância, teste $\mathrm{F}$, a $5 \%$ de probabilidade, e quando verificado efeito significativo, procedeu-se a comparação de médias pelo teste Scott e Knott, a 5\% de probabilidade.

\section{RESULTADOS E DISCUSSÃO}

Observou-se diferença estatística com relação ao número médio de lagartas encontradas no folíolo e flores apenas na terceira avaliação (7 DA2A), tendo como as menores médias os tratamentos tiodicarbe 320 , tiodicarbe $160+$ abamectina 9 e clorantraniliprole $20+$ abamectina 9 (g i.a ha ${ }^{-1}$ ) (Tabela 2).

Os tratamentos que apresentaram as melhores porcentagens de controle na última avaliação foram tiodicarbe 400 e clorantraniliprole $20+$ abamectina $9\left(\mathrm{~g}\right.$ i.a ha $\left.{ }^{-1}\right)$.

Tabela 2. Porcentagem de controle e número médio de lagartas-do-pescoço-vermelho ( $S$. bosqueella) em 10 folíolos novos e em 10 flores de amendoim avaliados ao longo do desenvolvimento. Arthur Nogueira, SP, safra 2018/19.

\begin{tabular}{|c|c|c|c|c|c|c|c|c|c|c|c|c|c|}
\hline \multirow{2}{*}{ Tratamentos } & \multirow{2}{*}{$\begin{array}{c}\text { Doses } \\
\left(\mathrm{g} \mathrm{i}^{\left.-\mathrm{a} \mathrm{ha}^{-1}\right)}\right.\end{array}$} & \multicolumn{3}{|c|}{ Prévia } & \multicolumn{3}{|c|}{$7 \mathrm{DA}_{1} \mathrm{~A}^{2}$} & \multicolumn{3}{|c|}{$7 \mathrm{DA} 2 \mathrm{~A}^{3}$} & \multicolumn{3}{|c|}{$7 \mathrm{DA}_{3} \mathrm{~A}^{4}$} \\
\hline & & $\mathrm{N}^{5}$ & $E^{6}$ & & $\mathrm{~N}$ & $\mathrm{E}$ & & $\mathrm{N}$ & $\mathrm{E}$ & & $\mathrm{N}$ & $\mathrm{E}$ & \\
\hline tiodicarbe & 240 & 0,0 & 0 & $\mathrm{a}$ & 0,8 & 50 & $\mathrm{a}$ & 2,8 & 35 & $\mathrm{a}$ & 0,8 & 57 & $\mathrm{a}$ \\
\hline tiodicarbe & 320 & 0,8 & 0 & $\mathrm{a}$ & 1,5 & 0 & $\mathrm{a}$ & 1,3 & 71 & $\mathrm{~b}$ & 0,8 & 57 & $\mathrm{a}$ \\
\hline tiodicarbe & 400 & 0,5 & 0 & $\mathrm{a}$ & 1,8 & 0 & $\mathrm{a}$ & 3,0 & 29 & $\mathrm{a}$ & 0,5 & 71 & $\mathrm{a}$ \\
\hline tiodicarbe $+a b$ & $160+9$ & 0,0 & 0 & $\mathrm{a}$ & 1,3 & 17 & $\mathrm{a}$ & 2,0 & 53 & $\mathrm{~b}$ & 1,0 & 43 & $\mathrm{a}$ \\
\hline tiodicarbe + abamectina & $240+9$ & 0,8 & 0 & $\mathrm{a}$ & 1,3 & 17 & $\mathrm{a}$ & 3,8 & 12 & a & 1,0 & 43 & $\mathrm{a}$ \\
\hline tiodicarbe + abamectina & $320+9$ & 0,8 & 0 & $\mathrm{a}$ & 0,8 & 50 & $\mathrm{a}$ & 3,0 & 29 & $\mathrm{a}$ & 0,8 & 57 & $\mathrm{a}$ \\
\hline
\end{tabular}


XVI Encontro Sobre a Cultura do Amendoim

15 a 17 de agosto de 2019 na Estação de Eventos Cora Coralina e FCAV/UNESP, Jaboticabal-SP

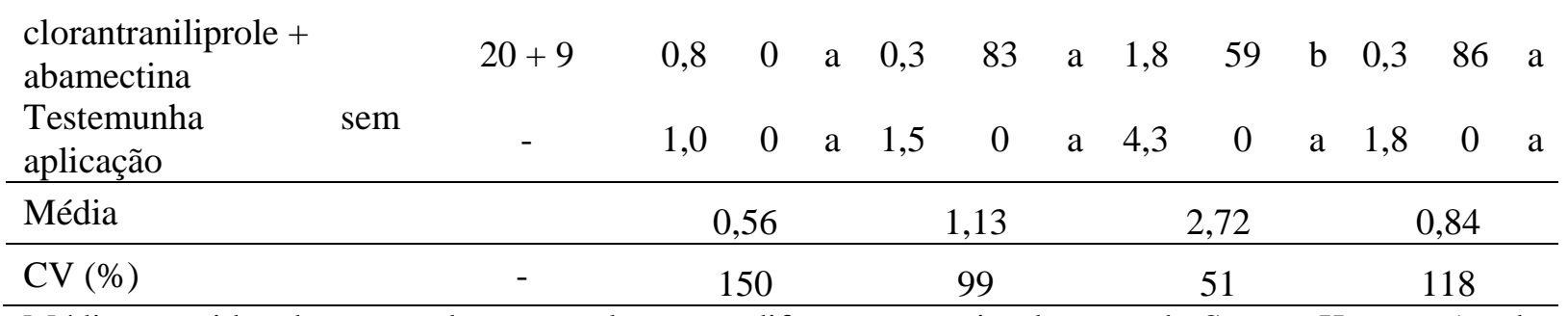

Médias seguidas de mesma letra na coluna não diferem entre si pelo teste de Scott e Knott a 5\% de probabilidade. ${ }^{1}$ produto comercial, ${ }^{2}$ sete dias após a primeira aplicação, ${ }^{3}$ sete dias após a segunda aplicação, ${ }^{4}$ sete dias após a terceira aplicação, ${ }^{5}$ número médio de lagartas, ${ }^{6}$ porcentagem de controle.

Os resultados de porcentagem de folíolos infestados mostraram que tiodicarbe 320 tiodicarbe 400, tiodicarbe $160+$ abamectina 9 , tiodicarbe $320+$ abamectina 9 e clorantraniliprole $20+$ abamectina 9 foram superiores a tiodicarbe 240 e tiodicarbe $240+$ abamectina 9 (g i.a ha $\left.{ }^{-1}\right)$ e testemunha sem aplicação (Tabela 3). Com relação a produtividade, todos os tratamentos apresentaram resultados semelhantes estatisticamente, com média de $6030 \mathrm{~kg} \mathrm{ha}^{-1}$, contudo a não aplicação de produtos químicos proporcionou perdas de até $27 \%$.

Tabela 3. Produtividade de amendoim e porcentagem de folíolos danificados por S. bosqueella. Arthur Nogueira, SP, safra 2018/19.

\begin{tabular}{lccc}
\hline \multicolumn{1}{c}{ Tratamentos } & Doses $\left(\mathrm{g} \mathrm{i.a} \mathrm{ha}^{-1}\right)$ & $\begin{array}{c}\text { Produtividade }(\mathrm{kg} \\
\left.\mathrm{ha}^{-1}\right)\end{array}$ & $\begin{array}{c}\text { Porcentagem de } \\
\text { folíolos } \\
\text { danificados }\end{array}$ \\
\hline tiodicarbe & 240 & $5645 \mathrm{a}$ & $54 \% \mathrm{~b}$ \\
tiodicarbe & 320 & $5738 \mathrm{a}$ & $46 \% \mathrm{c}$ \\
tiodicarbe & 400 & $5739 \mathrm{a}$ & $41 \% \mathrm{c}$ \\
tiodicarbe + abamectina & $160+9$ & $7184 \mathrm{a}$ & $39 \% \mathrm{c}$ \\
tiodicarbe + abamectina & $240+9$ & $5907 \mathrm{a}$ & $51 \% \mathrm{~b}$ \\
tiodicarbe + abamectina & $320+9$ & $6531 \mathrm{a}$ & $43 \% \mathrm{c}$ \\
clorantraniliprole & $20+9$ & $6261 \mathrm{a}$ & $33 \% \mathrm{c}$ \\
abamectina & - & $5233 \mathrm{a}$ & $70 \% \mathrm{a}$ \\
Testemunha sem aplicação & & 6030 & $47 \%$ \\
\hline Média & & 20 & 27 \\
\hline CV $(\%)$ & & &
\end{tabular}

Médias seguidas de mesma letra minúscula na coluna não diferem entre si pelo teste de Scott e Knott a $5 \%$ de probabilidade. ${ }^{1}$ produto comercial

\section{CONCLUSÕES}

A aplicação de tiodicarbe 320 , tiodicarbe 400, tiodicarbe 160 + abamectina 9, tiodicarbe 320 + abamectina 9 e clorantraniliprole 20 + abamectina $9\left(\mathrm{~g}\right.$ i.a $\left.\mathrm{ha}^{-1}\right)$ apresentaram as menores porcentagens de folíolos danificados. 


\section{Encontro Sobre a Cultura do Amendoim}

15 a 17 de agosto de 2019 na Estação de Eventos Cora Coralina e FCAV/UNESP, Jaboticabal-SP

A utilização de tiodicarbe 400 e clorantraniliprole $20+$ abamectina 9 (g i.a ha ${ }^{-1}$ ) proporcionaram as melhores porcentagens de controles na última avaliação.

Em termos de produtividade a não aplicação de produtos químicos proporcionou perdas de 27 $\%$.

\section{REFERENCIAS BIBLIOGRÁFICAS}

ABBOTT, W. S. A method for computing the effectiveness of an insecticide. Journal of Economic Entomology, College Park, v. 18, p. 265-267, 1925.

ALMEIDA, R. P. Recomendações Técnicas para o Manejo de Insetos-praga do Amendoinzeiro. Circular técnica Embrapa. n. 137, p.1-15, 2015.

CONAB. Companhia Nacional de Abastecimento. Produção de amendoim. Disponível em: http://www.conab.gov.br/. Acesso em: 01 de junho de 2019.

GALLO, D.; NAKANO, O.; SILVEIRA NETO, S.; CARVALHO, R.P.L.; BATISTA, G.C.; BERTI FILHO, E.; PARRA, J.R.P.; ZUCCHI, R.A.; ALVES, S.B.; VENDRAMIN, J.D.; MARCHINI, L.C.; LOPES, J.R.S.; OMOTO, C. Entomologia Agrícola, Piracicaba -SP. FEALQ, 2002, 920p. 